
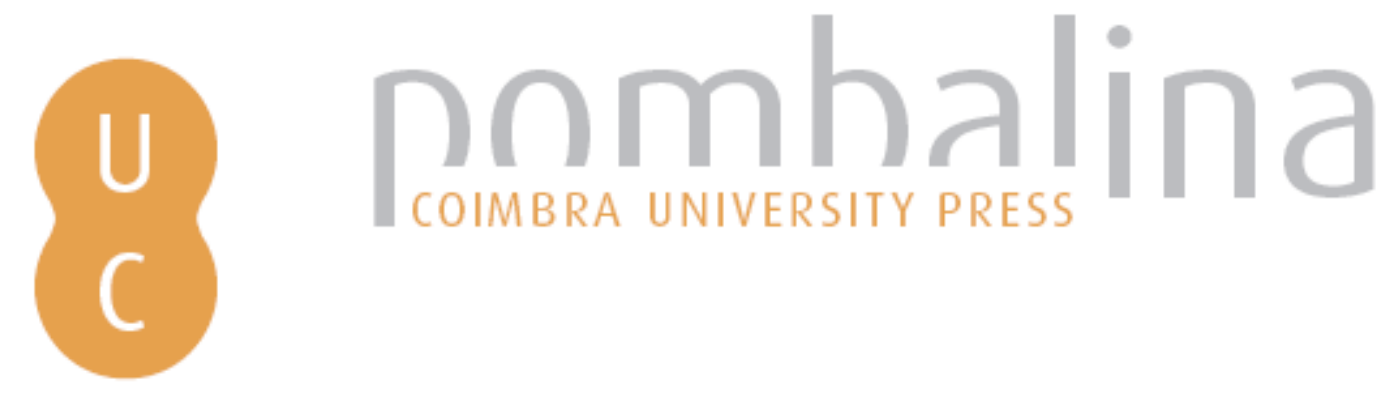

\title{
El poblamiento en el centro peninsular entre el Tardoimperio y la Alta Edad Media (ss. VVIII)
}

\author{
Autor(es): $\quad$ Tejerizo García, Carlos \\ Publicado por: Imprensa da Universidade de Coimbra \\ URL \\ persistente: URI:http://hdl.handle.net/10316.2/42111 \\ DOI: $\quad$ DOI:https://doi.org/10.14195/978-989-26-1353-6_5 \\ Accessed : $\quad$ 26-Apr-2023 16:28:23
}

A navegação consulta e descarregamento dos títulos inseridos nas Bibliotecas Digitais UC Digitalis, UC Pombalina e UC Impactum, pressupõem a aceitação plena e sem reservas dos Termos e Condições de Uso destas Bibliotecas Digitais, disponíveis em https://digitalis.uc.pt/pt-pt/termos.

Conforme exposto nos referidos Termos e Condições de Uso, o descarregamento de títulos de acesso restrito requer uma licença válida de autorização devendo o utilizador aceder ao(s) documento(s) a partir de um endereço de IP da instituição detentora da supramencionada licença.

Ao utilizador é apenas permitido o descarregamento para uso pessoal, pelo que o emprego do(s) título(s) descarregado(s) para outro fim, designadamente comercial, carece de autorização do respetivo autor ou editor da obra.

Na medida em que todas as obras da UC Digitalis se encontram protegidas pelo Código do Direito de Autor e Direitos Conexos e demais legislação aplicável, toda a cópia, parcial ou total, deste documento, nos casos em que é legalmente admitida, deverá conter ou fazer-se acompanhar por este aviso.

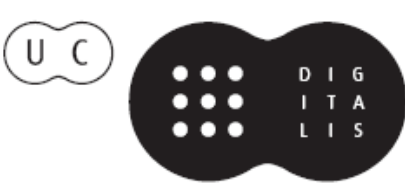




\section{Arqueologia \\ da transição:}

entre o mundo romano

e a Idade Média

Cláudia Teixeira, André Carneiro (coords.)

IMPRENSA DA UNIVERSIDADE DE COIMBRA

ANNABLUME 


\title{
El Poblamiento en El CENTRO PENINSUlar ENTRE \\ el Tardoimperio y la Alta Edad Media (ss. v-viiI) \\ The settlement in the centre of the peninsula between the Late Empire and the High Middle Ages (v-vinth centuries)
}

\author{
Carlos Tejerizo García (carlosteje@gmail.com) \\ Departamento de Geografía, Prehistoria y Arqueología, \\ Universidad del País Vasco / Euskal Herriko Unibertsitatea, UPV/EHU
}

\begin{abstract}
Resumo - O presente estudo analisa os padrões de povoamento no território situado entre os rios Adaja e Eresma na transição do final da economia imperial romana para o princípio da Alta Idade Média. A análise começa por uma caracterização tipológica e cronológica dos diversos pontos de povoamento, apresentando dados estratigráficos obtidos em escavações arqueológicas. Várias intervenções nos ultimos anos, no quadro da expansão de núcleos urbanos, trouxeram importantes dados estratigráficos que nos permitem colocar algumas hipóteses sobre este momento histórico.

Palabras clave - Povoamento; Arqueologia da Alta Idade Média; Bacia do Douro; Transição.
\end{abstract}

Summary - This paper analyses the settlement pattern in the territory between the Adaja and Eresma rivers during the transition between the end of Roman imperial economy and the beginning of the Early Middle Ages. This analyses starts from a typological and chronological characterization of the different settlements from which we have stratigraphic data through archaeological excavations. In this area there have been numerous archaeological interventions in recent years due to urban expansion which have provided important stratigraphic contexts and data that allow us to propose some hypotheses about this historic process.

KeYwords - Settlement pattern; Early Middle Age Archaeology; Duero basin; Transition.

\section{INTRODUCCIÓN ${ }^{1}$}

$\mathrm{El}$ análisis de la transición entre el mundo imperial romano y los primeros momentos de la Alta Edad Media es un tema que está atrayendo reciente-

${ }^{1}$ Trabajo realizado en el marco del proyecto de investigación "Desigualdad en los paisajes medievales del norte peninsular: los marcadores arqueológicos”, HUM 2012-32514, de la actividad del "Grupo de Investigación en Patrimonio y Paisajes Culturales / Ondare eta Kultur Paisaietan Ikerketa Taldea” (IT315-10) financiado por el Gobierno Vasco, de la UFI 11/02 "Historia, Pensamiento y Cultura Material” y la Unidad Asociada CSIC-UPV/EHU 'Grupo de Estudios Rurales'. Agradezco a Juan Antonio Quirós, Alfonso Vigil-Escalera, Javier Martínez y Clara Hernando los comentarios al texto. 
mente la atención de los investigadores en Arqueología. Hasta hace unos años el estudio de este momento histórico había estado dominado por los análisis realizados desde el punto de vista de los escasos documentos conservados, pero, progresivamente, se han ido incorporando los avances desde el análisis de la cultura material que han permitido replantear muchos de los debates sobre el poblamiento altomedieval.

La Arqueología de la Alta Edad Media es una disciplina joven, si bien el análisis de la Cuenca del Duero, espacio geográfico que centra el análisis de este trabajo $^{2}$, tiene algo más de trayectoria historiográfica con respecto a otras zonas de la Península Ibérica. Sin embargo, gran parte de los análisis arqueológicos del poblamiento altomedieval en este área se han sustentado de forma empírica, principalmente, en los datos provenientes de las excavaciones en las necrópolis e iglesias altomedievales y en los datos proporcionados por prospecciones más o menos sistemáticas junto con la recopilación de materiales dispersos. Sólo en algunas ocasiones se han visto complementados con algunas excavaciones aisladas, normalmente muy antiguas o de escasa extensión.

Las ventajas que ofrecen las prospecciones son indudables; no sólo ofrecen un método no destructivo de estudio (y más económico) sino que es una herramienta que compagina la densidad de análisis con la extensión territorial y cronológica. Por el contrario, los mayores inconvenientes de este tipo de metodologías son el cronológico y el taxonómico. En cuanto a las dataciones, este tipo de estudios, al carecer de estratigrafías, tienen que apoyarse normalmente en "fósiles directores" que delimitan, de forma muy aproximada, un marco cronocultural (por ejemplo, clasificar como "tardorromano" la asociación tégula - Terras Sigillatas tardías); cronología que se complica a medida que se adentra en los siglos v al viIr. Por otro lado, se presenta la dificultad de clasificar el tipo de poblamiento relacionado con el material en superficie, que genera débiles sistemas de categorización derivados en muchas ocasiones de la ausencia de estructuras que acompañen al material en superficie (por ejemplo, la anterior asociación tégula y sigillatas relacionado sistemáticamente con el asentamiento "tipo villa") y a la falta de marcos teórico-interpretativos.

La importante información ofrecida por el análisis del material en superficie debe ser, pues, complementada con los datos provenientes de contextos estratigráficos que, hasta hace unos pocos años, eran muy escasos. Este panorama ha cambiado radicalmente debido a la expansión urbanística de las últimas dos décadas, que ha generado una inmensa cantidad de datos, ahora sí, provenientes de excavaciones estratigráficas ${ }^{3}$. Contamos, por tanto, con la masa de datos

\footnotetext{
${ }^{2}$ Este trabajo forma parte de mi proyecto de Tesis Doctoral en torno al análisis del poblamiento y la estructuración social altomedieval en la Cuenca del Duero.

${ }^{3}$ Excavaciones que en ocasiones han dejado mucho que desear en cuanto a la metodología de registro, la calidad de los procedimientos o los sistemas de registro (Vigil-Escalera 2011) y
} 
suficiente para hacer algunas aproximaciones a estos momentos de transición desde un punto de vista arqueológico y estratigráfico.

El espacio elegido como marco "experimental" de análisis comprende un territorio delimitado por el río Duero al norte, el Sistema Central al sur y, grosso modo, el espacio comprendido entre las cuencas del río Eresma y el Adaja. En grandes líneas es un contexto geográfico relativamente uniforme conformado por las llamadas campiñas meridionales del Duero, grandes espacios relativamente llanos salpicados de pequeños montes y elevaciones de escasa altura relativa, interrumpiéndose al sur con el piedemonte del Sistema Central.

La elección de este territorio responde a dos criterios: por un lado, la huida voluntaria del uso de marcos geopolíticos actuales (provincias, localidades, Comunidades Autónomas...) que responden, en mayor o menor medida, al fomento de identidades políticas contemporáneas que poco tienen que ver con las identidades sociales de las comunidades del pasado; por otro, la alta densidad de yacimientos arqueológicos excavados en esta zona (ver figura 1).

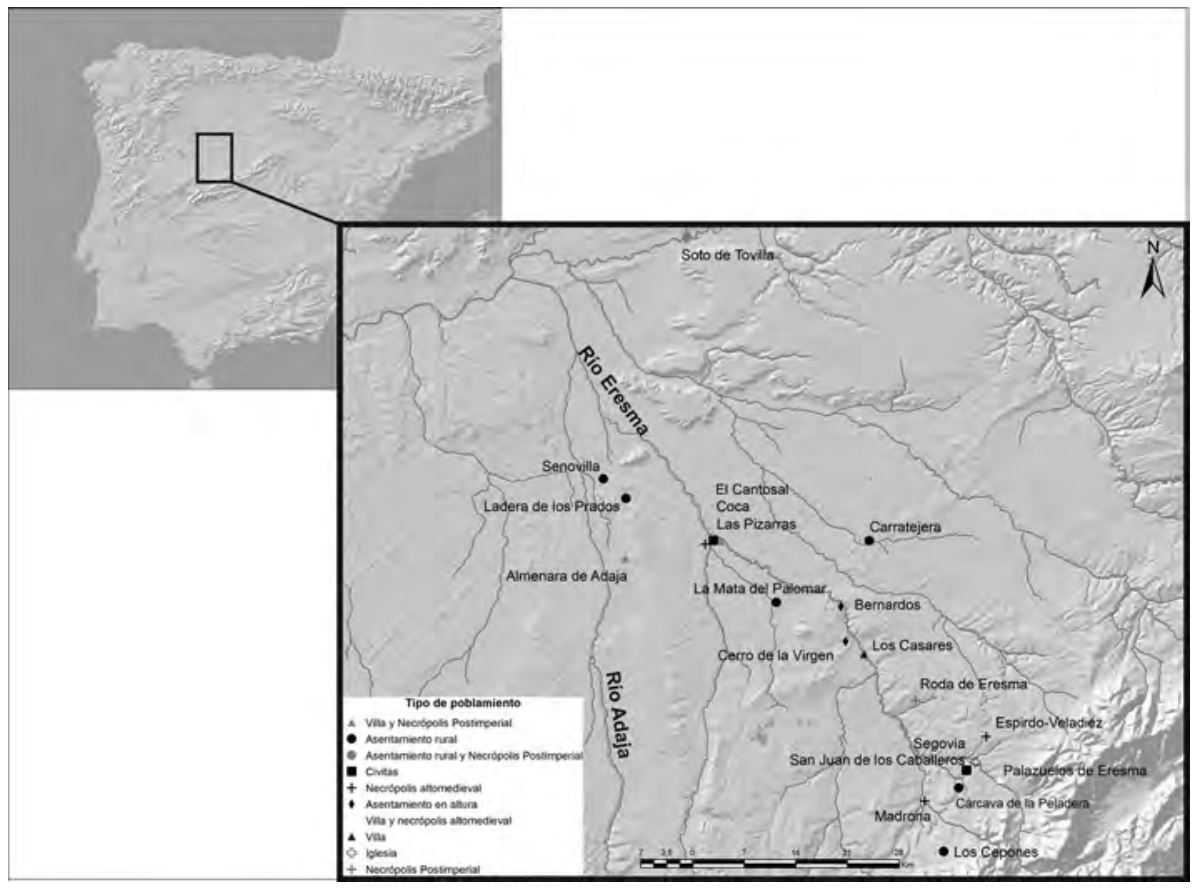

Figura 1 - Mapa con la distribución y tipo de yacimientos en el área de estudio.

que deben ser objeto de una profunda crítica estratigráfica y arqueológica (además de ética y social) para poder utilizarse como fundamentación empírica de los estudios. 


\section{LA MATERIALIDAD ARQUEOLÓGICA: UNA SÍNTESIS}

En total se han podido recopilar hasta 20 excavaciones arqueológicas con algún tipo de estratigrafía en el territorio objeto de estudio cuya secuencia de ocupación se encuentra en algún momento entre los siglos v y Ix. Estos contextos se exponen en función de una categorización basada en el tipo de poblamiento al que se pueden adscribir; de esta manera se han diferenciado villas tardoimperiales, entidades rurales menores, necrópolis postimperiales, antiguas civitas, ocupaciones en altura, necrópolis altomedievales y asentamientos rurales altomedievales. Si bien, como veremos, esta categorización no es estática en el tiempo ya que en algunos casos han coincidido espacialmente varios tipos de poblamiento. De cada uno de ellos se presentarán algunos casos significativos que permitan caracterizar el tipo de poblamiento.

\subsection{Las villas tardoimperiales}

Las villas tardoimperiales son los contextos arqueológicos de este período mejor conocidos tanto en la Península Ibérica como en la cuenca del Duero (Chavarría Arnau 2008). En general se definen por la presencia de un gran edificio con sus distintas dependencias que centraliza la producción latifundista de un territorio más o menos extenso así como por servir de residencia y expresión simbólica de una aristocracia terrateniente. Entre el Adaja y el Eresma se encuentran las villas de Almenara de Adaja (Almenara-Puras, Valladolid), Los Casares (Armuña, Segovia), Palazuelos de Eresma (Segovia) y la recientemente excavada villa suburbana de Las Pizarras con las necrópolis asociadas, en las proximidades de la ciudad de $\mathrm{Coca}^{4}$.

La villa de Almenara de Adaja es un yacimiento conocido desde antiguo. La villa, situada en un terreno llano en altura a $15 \mathrm{~km}$ de la ciudad de Coca ${ }^{5}$, fue documentada por primera vez en 1887 a través del descubrimiento de un gran mosaico tardoimperial. A partir de entonces, y de manera intermitente, se han ido sucediendo varias campañas de excavaciones que han dado como resultado la excavación de una villa romana de cerca de $2500 \mathrm{~m}^{2}$ y con un gran cuerpo rectangular articulada en torno a un patio central de 10x12 m que ha sido calificado de "pequeño palacio rural” (García Merino e Sánchez Simón 2004 p. 193).

${ }^{4}$ Nota do Editor: ver contributo de Cesáreo Pérez Gonzalez e Olivia Reyes Hernando neste volume.

${ }^{5}$ La situación de la villa de Almenara de Adaja a escasos $15 \mathrm{~km}$. de la civitas de Coca ha sido un argumento para relacionarla con la familia imperial teodosiana (Mañanes Pérez 1992). Este argumento de la vinculación de los yacimientos segovianos con la familia teodosiana es un topos común en los estudios históricos y arqueológicos sobre muchos de los yacimientos aquí estudiados y que son un claro ejemplo de las interpretaciones arqueológicas subalternas de la documentación escrita que poco suelen añadir a la interpretación de los procesos históricos. 
Aunque la villa presenta una importante fase de época altoimperial, el edificio que ha quedado actualmente es una construcción que se iniciaría a comienzos del siglo IV y que tuvo al menos una importante reforma a mediados de esa centuria (García Merino e Sánchez Simón 2004).

El abandono definitivo de la villa como residencia aristocrática se sitúa arqueológicamente a finales del siglo v o inicios del vi "sin que se aprecie la presencia de materiales que lleven a pensar en una reocupación del edificio en siglos posteriores" (Chavarría Arnau 2008: 98) salvo por una tumba de época visigoda documentada por G. Nieto pero de la que no existen más datos (García Merino e Sánchez Simón 2004: 182). Este abandono viene avalado por la secuencia estratigráfica, detectándose fenómenos de expolio muy próximos en el tiempo a su abandono como villa residencial ${ }^{6}$. Es más, en alguna de las publicaciones sobre la villa se hace mención directa sobre la presencia, en niveles asociados a la destrucción, de material constructivo con "cerámica común” y "cerámica tosca, porosa, de corte granuloso, con desgrasantes de cuarzo, en tonos pardos o negros, con formas de cuenco y recipientes con tapadera" así como de "cerámicas grises estampadas en el nivel de destrucción del edificio" (García Merino e Sánchez Simón 2011: 181). El conjunto cerámico publicado de los niveles de destrucción de la villa muestran algunos fragmentos que podrían datarse, junto con la cerámica estampillada, hacia el último tercio de la $\mathrm{V}$ centuria mostrando quizá la presencia de un poblamiento altomedieval en los entornos de la villa, como parece mostrarse también a través de la presencia de la tumba "visigoda". A 200 metros de la villa se excavó una tumba de una mujer adulta cuyo ajuar (cuenco de TSHt, un posible huso y tabas de animales) parecen relacionarla con las necrópolis postimperiales (vid. infra).

Otra villa tardoimperial cercana a Cauca es la villa de Los Casares. Esta villa fue documentada en 1987 y posteriormente analizada por fotografía aérea, que permitió una primera aproximación a su planta (Regueras Grande e Del Olmo 1997). A partir de 2005 la villa ha sido objeto de un proyecto de investigación con varias campañas de prospección y excavación entre 2005-2007 (Storch De Gracia 2010). Dichas excavaciones se han centrado en algunas de las habitaciones principales de la villa tardoimperial documentando varias fases de ocupación.

\footnotetext{
${ }^{6}$ No sólo se detectaron zanjas de expolio (por ejemplo, en la habitación n. ${ }^{\circ} 20$ ) y huellas de hoguera sobre algunos mosaicos, sino que "las tejas en algunos puntos no son tan abundantes como cabría esperar si nada hubiera alterado la formación del depósito, lo que indica un expolio muy temprano" (García Merino e Sánchez Simón 2011: 181).

${ }^{7}$ Término excesivamente poco expresivo y que apenas ofrece información de ningún tipo que debería ser desechado en las publicaciones arqueológicas, al menos de estos momentos cronológicos en favor de otros criterios de clasificación que permitan una mejor caracterización del material arqueológico.
} 
En lo que respecta a su abandono, I. Rodríguez sugiere una ocupación continuada del espacio entre época altoimperial "hasta, al menos, el siglo Iv" (Rodríguez López 2010: 134). Sin embargo, algunos de los materiales cerámicos publicados podrían apuntar, de nuevo, a momentos de abandono, o de un cambio significativo en la funcionalidad del contexto, en torno a mediados de la $\mathrm{v}$ centuria.

\subsection{Entidades rurales menores}

La documentación escrita hace referencia a la presencia en las zonas rurales de "entidades menores" junto a los grandes latifundios vilicarios. Sin embargo, el reflejo arqueológico de estos en la Península Ibérica es muy escaso debido a la atención preferencial que han tenido los espacios residenciales de las villas. Actualmente se conocen algunos contextos rurales coetáneos a las villas pero que no responden al mismo tipo de poblamiento y que, debido al escaso conocimiento que se tiene sobre ellos, tienen una difícil caracterización tipológica y social; en nuestro caso, serían los yacimientos de Soto de Tovilla (Tudela de Duero, Valladolid) y Carratejera (Navalmanzano, Segovia).

Éste último ha sido objeto de dos campañas de excavación en 2003 y 2007 (Marcos Contreras, e alii 2010). Se sitúa en un cerro junto a la margen izquierda del río Malucas, en el espacio interfluvial entre los ríos Cega y Eresma. Las excavaciones registraron un total de 155 estructuras correspondientes a dos fases distintas; la primera del Bronce Medio y la segunda denominada "tardorromana". Esta segunda deparó algunas estructuras como un horno de cocción de cerámica o materiales constructivos, varias fosas de almacenamiento utilizadas como basureros en el momento final de uso o una posible canalización de agua construida a partir de tégulas y ladrillos.

Destaca la estructura 1517, excavada en el suelo y con planta de $3 \times 2,77 \mathrm{~m}$ y $1,13 \mathrm{~m}$ de profundidad. En la base se registraron cuatro agujeros de poste circulares en las esquinas. El material hallado en el relleno se compone por una importante cantidad de objetos de metal, destacando una pátera y un caldero, un aplique circular con un crismón central calado, dos pasarriendas y una campani1la, así como un as de época de Tiberio. En cuanto a la cerámica, se localizaron fragmentos de TSHt, lucernas, fragmentos de ánfora así como grandes contenedores y ollas de cocina (sin descripción) ${ }^{8}$. Los excavadores la interpretaron como un "habitáculo semirrupestre que serviría de sótano, nevero, bodega o silo, sobre el que se construye un edifico o casa, o bien que simplemente fuera un recinto protegido por una cubierta" (Marcos Contreras, et alii 2010: 383).

\footnotetext{
${ }^{8}$ Información extraída de las fichas estratigráficas del informe correspondiente (Strato 2003).
} 
Dadas sus características y el contexto cronológico en el que se inserta, es posible que se trate de un fondo de cabaña como los que se localizan en los asentamientos rurales a partir de momentos avanzados de la quinta centuria (vid. Infra). De ser así, y el resto de estructuras estar en conexión con ella, esta interpretación modificaría la adscripción cronológica del yacimiento, así como su interpretación socio-económica. A falta de más datos y de una publicación detallada de los materiales y su contexto estratigráfico, hay que ser cauteloso con esta hipótesis. Por un lado, parte de los materiales descritos en la mencionada publicación, tanto del relleno de esta estructura como en el yacimiento en general, son de clara cronología tardoimperial, aunque podrían haber llegado hasta estos rellenos como elementos residuales debido a los procesos de amortización; por otro, la datación por termoluminiscencia llevada a cabo en un horno dio como resultado una amplia horquilla $(265 \pm 139$ d.C) que podría corresponder desde mediados del siglo iI hasta inicios del $\mathrm{V}$ para la última cocción efectuada en el horno.

Se plantea, por tanto, que algunas, si no la mayoría de las estructuras de $\mathrm{Ca}-$ rratejera, pudieran pertenecer al mundo altomedieval más que al tardoimperial. Hipótesis que habrá que confirmar con el estudio detallado y estratigráfico de los materiales cerámicos en busca de posibles marcadores post quem del siglo v-vI.

\subsection{Las necrópolis postimperiales}

El fenómeno de las necrópolis postimperiales (sensu Vigil-Escalera 2009) es otro tipo de contexto ampliamente reconocido en el contexto de la cuenca del Duero. En la zona de estudio se han excavado algunos de los contextos más significativos como es la de Roda de Eresma (Segovia) y otras menos tratadas en la bibliografía como la necrópolis de Soto de Tovilla (Tudela de Duero, Valladolid), las tumbas recientemente excavadas en Las Pizarras, junto con la tumba documentada en la villa de Almenara de Adaja.

La necrópolis de Roda de Eresma fue hallada durante unas prospecciones realizadas por Antonio Molinero en 1948 en la que se descubrieron cinco tumbas que fueron catalogadas como "hispano-romanas" y dos estelas funerarias. Fue excavada en 1950, añadiendo 28 tumbas más a las anteriores con "abundantes piezas de cerámica, vidrios, herramientas de hierro, tenazas de herrero y martillos, tachuelas, una lucerna, brazaletes, etc.” (Molinero Pérez 1950: 647). En prospecciones más recientes de 1987 se localizaron algunos restos de TSHt, "cerámica común", recipientes de vidrio, armas, herramientas, dos inscripciones funerarias reaprovechadas en una tumba y otros elementos de bronce y hierro que apuntan a estas cronologías postimperiales. Desgraciadamente no se ha conservado una planta de las tumbas, lo que limita enormemente las posibilidades de análisis de este cementerio.

Se excavaron 33 tumbas en total que, de forma mayoritaria, son fosas simples con ataúd (reconocido en, al menos, 27 de ellas). De ellas, 28 cuentan con 
algún elemento de ajuar y en 5 de ellas no se recuperó ningún objeto. Junto a las clásicas cerámicas de los ciclos finales de Terra Sigillata o de "cerámica común", (botellas, jarras y platos fundamentalmente) y diferentes elementos de hierro (en 9 sepulturas; el 27\%), se registró una importante colección de vidrios que estaban presentes en, al menos, 17 tumbas (casi el 52\%) y que presentan cuatro grupos fundamentales: jarras, cuencos, vasos cerrados y ungüentarios. Es especialmente relevante la masiva presencia de vidrio en este cementerio si lo comparamos con otros del mismo entorno y cronología?.

En cuanto a Soto de Tovilla, este yacimiento se encuentra en una terraza fluvial de la margen izquierda del nivel del río Duero, a $20 \mathrm{~m}$ sobre este, que ofrece un lugar óptimo para la agricultura; actividad que ha afectado enormemente al yacimiento. Se documentaron una serie de paramentos pertenecientes a uno o varios edificios, pero de cronología desconocida. La necrópolis se emplaza al sur de los paramentos de mampostería y está formada por 26 tumbas en dos espacios diferenciados (Martín Rodríguez e San Gregorio Hernández 2008). Tipológicamente se registran dos tipos mayoritarios de tumbas: en fosa simple, la gran mayoría; y dos en cista de teja; al menos 15 de las primeras registraron restos de ataúdes. 15 enterramientos (el 57,7\%) presentaron algún elemento de ajuar. En 12 de ellas se registró algún tipo de recipiente cerámico entre los que está presente de forma repetitiva alguna forma de vaso junto con elementos de TSHt o de “cerámica común". Destaca la presencia en la sepultura 107, perteneciente a un infantil, de un plato y una jarra de cerámica de "Terra sigillata gris, también denominada paleocristiana... decorado con un círculo de rosetas impreso en su interior", que podría estar indicando una cronología en torno a la mitad o finales del siglo v. Las otras tres contenían una pulsera de cuentas de ámbar y azabache una de ellas, un útil de hierro la segunda y el tercero, inhumado en decúbito lateral contenía un mango tallado en hueso, un cuchillo y dos punzones de hueso. Otros elementos significativos serían un cuchillo "tipo-Simancas" y la presencia de una cabeza de caballo en la sepultura 276. Los autores sitúan cronológicamente estas sepulturas en los siglos IV-v (Martín Rodríguez e San Gregorio Hernández 2008: 31).

\subsection{Necrópolis altomedievales}

A partir de finales del siglo $\mathrm{v}$ e inicios del siglo vi se observan importantes cambios en la ritualidad funeraria con respecto a los momentos precedentes.

${ }^{9}$ En Las Merchanas (Lumbrales, Salamanca) sólo el 6\% de las tumbas cuentan con vidrios; en La Morterona (Saldaña, Palencia) se sitúa en el 12\%; en San Miguel del Arroyo (Valladolid) llega al 23\%; y Simancas (Valladolid), la paradigmática necrópolis postimperial, únicamente el $3 \%$ de las tumbas cuenta con algún elemento de vidrio (a partir de los datos de Fuentes Domínguez 1989) 
El contraste entre los contextos funerarios postimperiales y los altomedievales datados a partir de finales de la quinta centuria e inicios del siglo vi es muy destacada (Tejerizo García 2011) y obedecen a una diferente estructuración socio-económica e identitaria de las comunidades enterradas.

La necrópolis altomedieval más significativa cualitativa y cuantitativamente es Madrona (Segovia). Esta se encuentra situada al noroeste de la población actual, en las últimas estribaciones de la Sierra del Quintanar, en la zona de confluencia de los ríos Milanillos y Eresma, a unos $7 \mathrm{~km}$ de la ciudad de Segovia. Fue descubierta y excavada en la década de los 50 por Antonio Molinero, quién documentó un total de 351 sepulturas y recientemente revisada por A. Jepure (2012).

La planta de los enterramientos refleja una mayoritaria disposición en dirección E-O, aunque con importantes desviaciones e, incluso, con algunas tumbas con una orientación radicalmente opuesta en dirección NE-SO, que indican varias fases de un uso dilatado de este yacimiento. De los 351 enterramientos, 165 cuentan con algún tipo de ajuar (algo más del 47\% de ellas) aunque las diferencias entre estos ajuares son muy significativas, reflejando asimetrías sociales y económicas dentro de la comunidad. En cuanto al tipo de tumbas, sobresalen en número las compuestas por muretes de piedras de gran tamaño junto con las fosas simples. Igualmente se documentó un número elevado de sarcófagos, con 32 ejemplares en todo el conjunto funerario.

La cantidad y calidad de los ajuares es muy significativa, lo que hace de Madrona una de las necrópolis más ricas junto con un reducido grupo de yacimientos de similares características, caso de Duratón o Carpio de Tajo. Se trata de un conjunto típico en las necrópolis altomedievales consistentes en ajuares de tipo personal en forma de broches, fíbulas y hebillas de diversos tipos, collares, pendientes, brazaletes... y la presencia de algunos puñales y regatones, identificados normalmente con armas. La ausencia de broches de cinturón liriformes podrían estar indicando una cronología centrada en el siglo vi y principios del vir para el conjunto funerario.

La necrópolis de El Cantosal (Segovia) está situada en el pago del mismo nombre en las proximidades de la ciudad de Coca (Lucas de Viñas 1971). Se trata de una necrópolis que, a pesar del escaso tamaño conocido (un total de 10 enterramientos), es especialmente heterogénea en todos los sentidos. En primer lugar, encontramos una diversidad en las formas de enterramiento que parecen reflejar momentos cronológicos distintos y, por tanto, o un uso reiterativo del mismo espacio funerario en diversos momentos o un uso continuado durante un periodo largo de tiempo. Esta segunda opción parece más probable, pues los pocos enterramientos recuperados respetan una orientación W-E. En El Cantosal encontramos enterramientos en ánfora (enterramiento 2), en estructuras que usan teja, en fosa simple o fosa simple rodeada de piedras, una cista de piedras, un sarcófago monolítico "reutilizado" y una fosa con un muro de piedras irregulares bastante homogéneas formando una estructura cuadrangular de esquinas 
redondeadas. Este uso prolongado en el tiempo se confirma también a través del enterramiento 7 , en el que se encontraron dos individuos enterrados, un conjunto de huesos a los pies y otro enterramiento por debajo de la tumba.

Únicamente dos de las tumbas ofrecieron ajuar, consistente en un jarrito cerámico en el enterramiento $9 \mathrm{y}$ un anillo en el enterramiento 8. Junto a estos objetos se documentó un pequeño conjunto de cerámicas que se dividieron en dos grupos; las cerámicas sigillatas y las cerámicas grises. Por último, hay que hacer mención a un objeto de metal (un "osculatorio") que, según afirma Blanco García (1997: 389), parece que se halló en el interior de un plato "gris" en esta necrópolis, de forma clandestina.

La escasez de datos sugiere precaución ante su adscripción cronológica, aunque las tipologías mayoritarias de tumbas (salvo el ánfora), el tipo de ajuar encontrado y el tipo de cerámicas recuperadas parecen sugerir un momento de uso posterior al siglo VI para el conjunto conocido, aunque no se descarta una ocupación continuada de la necrópolis desde época imperial hasta un límite altomedieval muy inseguro, que encajaría mejor con una necrópolis suburbana, como parece ser el caso.

Junto a estos dos contextos encontramos también Espirdo-Veladiez (Segovia) como ejemplo de necrópolis altomedieval (Jepure 2004).

\subsection{Antiguas civitas}

El área geográfica objeto de estudio fue encuadrada por el aparato administrativo imperial dentro de las áreas jurisdiccionales de las ciudades de Segovia y de Cauca, de las que se tiene un conocimiento arqueológico muy somero para época tardoimperial y altoimperial (Blanco García, 2010; Santiago Pardo e Martínez Caballero 2010).

En cuanto a Segovia a partir del siglo v apenas tenemos referencias arqueológicas dentro de la propia ciudad, pero sí algunas en textos documentales. En cuanto a las escasos datos arqueológicos se conoce la construcción a lo largo del siglo vi de la iglesia de San Juan de los Caballeros (Santiago Pardo e Martínez Caballero 2010), siendo esta la única iglesia que encontramos en el área de estudio. Sabemos a través de los textos conciliares que a finales de la sexta centuria existe una sede episcopal en Segovia y que participaba activamente en la política religiosa del momento con la participación de un total de seis obispos en los concilios entre los Concilios III y el XVI de Toledo (Alonso Ávila 1984-1985). Sin embargo, el origen de esta sede parece detectarse anteriormente en las cartas del obispo Montano a Toribio en el segundo tercio de esta misma centuria en un contexto religioso marcado por las disputas con el priscilianismo y la reorganización institucional de la iglesia en la Meseta (Isla Frez 2000-2001: 51).

De la zona central de Cauca a partir del siglo iv únicamente existen algunos datos aislados, como la presencia de cerámicas estampilladas en la zona de la 
C/Azafranales, donde se excavó un pozo del que se han conservado hasta 4,5 m de profundidad (Blanco García 2010: 234), así como menciones a algunos materiales como pizarras de tipo Lerilla, fíbulas o broches de cinturón asociadas a un momento altomedieval (Blanco García 1997: 390). A esto se une la presencia de un horno de cocción cerámica en la zona de Las Negreras (Blanco García 2010: 249). La pérdida de funciones administrativas de la ciudad es significativa a partir del siglo VI, cuando fue adscrita al obispado segoviano (Martínez Caballero e Santiago Pardo 2010: 100).

\subsection{Las aldeas altomedievales}

En los últimos quince años se han producido numerosas excavaciones sobre contextos rurales altomedievales en toda la Península Ibérica que han generado una ingente cantidad de información. Esto se debe principalmente al modelo de expansión urbanística implementado en Castilla y León que ha priorizado los entornos periurbanos y las vías de comunicación. La información arqueológica ha estado, pues, determinada por el tipo de intervenciones llevadas a cabo, ligadas principalmente a la construcción de las líneas de Alta Velocidad, infraestructuras menores (acueductos, canalizaciones) o pequeños seguimientos de obra.

Precisamente, el área de estudio elegida tiene algunos de los contextos rurales altomedievales más significativos de toda la cuenca del Duero. Esto son, principalmente Senovilla (Olmedo, Valladolid), Ladera de los Prados (Aguasal, Valladolid), Navamboal (Íscar, Valladolid), La Mata del Palomar (Nieva, Segovia), Cárcava de la Peladera (Hontoria, Segovia) y Los Cepones (La Losa, Segovia) ${ }^{10}$.

El yacimiento de Senovilla ${ }^{11}$ se encuentra a $1 \mathrm{~km}$ de la actual localidad de Olmedo en las proximidades del arroyo Torcas y el bodón de La Veguilla (Strato 2007). Durante la excavación, llevada a cabo en 2007, se documentaron 110 estructuras. La mayoría de ellas son de formato rehundido que se clasifican en cuatro tipos básicos: fondos de cabaña, zanjas, silos y cubetas indeterminadas. Se documentaron cerca de una docena de posibles fondos de cabaña, estructura doméstica muy común en los contextos altomedievales en toda Europa. Llaman la atención las estructuras 23 y 23 bis, cortando la primera a la segunda y mostrando, al menos, dos fases sucesivas de construcción y ocupación del yacimiento y el carácter móvil de las unidades de ocupación.

${ }^{10}$ Los yacimientos de Ladera de los Prados, Navamboal, La Mata del Palomar y Cárcava de la Peladera son objeto de un estudio monográfico (J. A Quirós Castillo 2013), por lo que no se describirán aquí.

${ }^{11}$ Para esta descripción se han utilizado los datos de los informes de excavación. Agradecemos especialmente a ARATIKOS y a STRATO y en particular a Francisco Javier Sanz y Ángel Palomino su disponibilidad y paciencia. 
Se excavaron alrededor de 25 silos de almacenamiento que han mostrado un alto grado de arrasamiento del entorno. La estructura 100, la mejor conservada, tiene unas medidas de 1,55 $\mathrm{m}$ de diámetro, que posiblemente corresponda a su diámetro máximo, y $90 \mathrm{~cm}$ de profundidad, por lo que se puede hipotetizar que los diversos procesos postdeposicionales habrían destruido entre $50 \mathrm{~cm}$ y un metro de la cota de frecuentación original en muchas de las estructuras del yacimiento.

Un elemento muy característico de este yacimiento son las numerosas zanjas que se dispersan por el contexto excavado, registrándose hasta 14 de estas estructuras. Aunque su interpretación funcional no es clara, no se descarta que pudieran ser zanjas de cimentación de estructuras de separación de las distintas unidades ocupacionales del asentamiento, como se ha mostrado en otros contextos similares de la Península Ibérica (Vigil-Escalera 2007). De ser así, se trataría de una significativa organización del espacio aldeano que nos pondría en relación con estructuras de propiedad de diferentes unidades ocupacionales parceladas dentro del mismo marco de producción aldeana.

Como es común en los contextos aldeanos de la cuenca del Duero, el alto grado de arrasamiento ha deparado una escasa cantidad de estructuras aéreas. En Senovilla se han documentado únicamente cuatro estructuras de piedra, todas ellas muy sencillas de mampostería de caliza y arenisca trabadas en seco. La más completa es la estructura 28, con dos paramentos de piedra mediante un doble lienzo de mampostería de piedras relleno por cantos cuarcíticos y materiales constructivos que dibujan una planta cuadrangular. Estos paramentos amortizan un posible silo de almacenamiento (la estructura 100) como consecuencia de las diversas fases de ocupación y construcción.

$\mathrm{El}$ análisis preliminar de los materiales cerámicos parece datar este entorno entre finales de la quinta centuria y un momento indeterminado de la Alta Edad Media, posiblemente no más allá de la octava centuria.

El yacimiento de Los Cepones, situado en la localidad de La Losa. Es el más meridional de todos los yacimientos aquí analizados y se encuentra al pie de las sierras del Sistema Central. La pequeña intervención llevada a cabo a partir de la construcción de la Autopista A-6 documentó la presencia de varias estructuras aéreas hechas en mampostería de piedra (Strato 2002). Destaca la llamada "estructura 4" (ver figura 2) situada en el sector 2. Se trata de un edificio con planta en forma de "L", con los extremos orientados hacia el suroeste y el noroeste. El "Ala Menor" mide unos 9,5x4 m mientras que el "Ala Mayor" tiene unas medidas de $13 \times 5,5 \mathrm{~m}$ con cerca de $110 \mathrm{~m}^{2}$ de espacio útil. Frente a las estructuras del sector I, el tamaño de las piedras es mayor y son esencialmente grandes bloques de granito, gneiss y esquisto careado de procedencia local junto con piedras calizas foráneas. Se ha registrado la presencia de tres posibles puertas; dos en el muro norte y otro en la mitad del muro sur y algunos lienzos que podrían indicar la compartimentación en distintas habitaciones, aunque no se ha podido determinar con claridad. 
$\mathrm{El}$ análisis preliminar de los materiales podría estar indicando una cronología del yacimiento centrada en los siglos v y viI (Strato 2002).

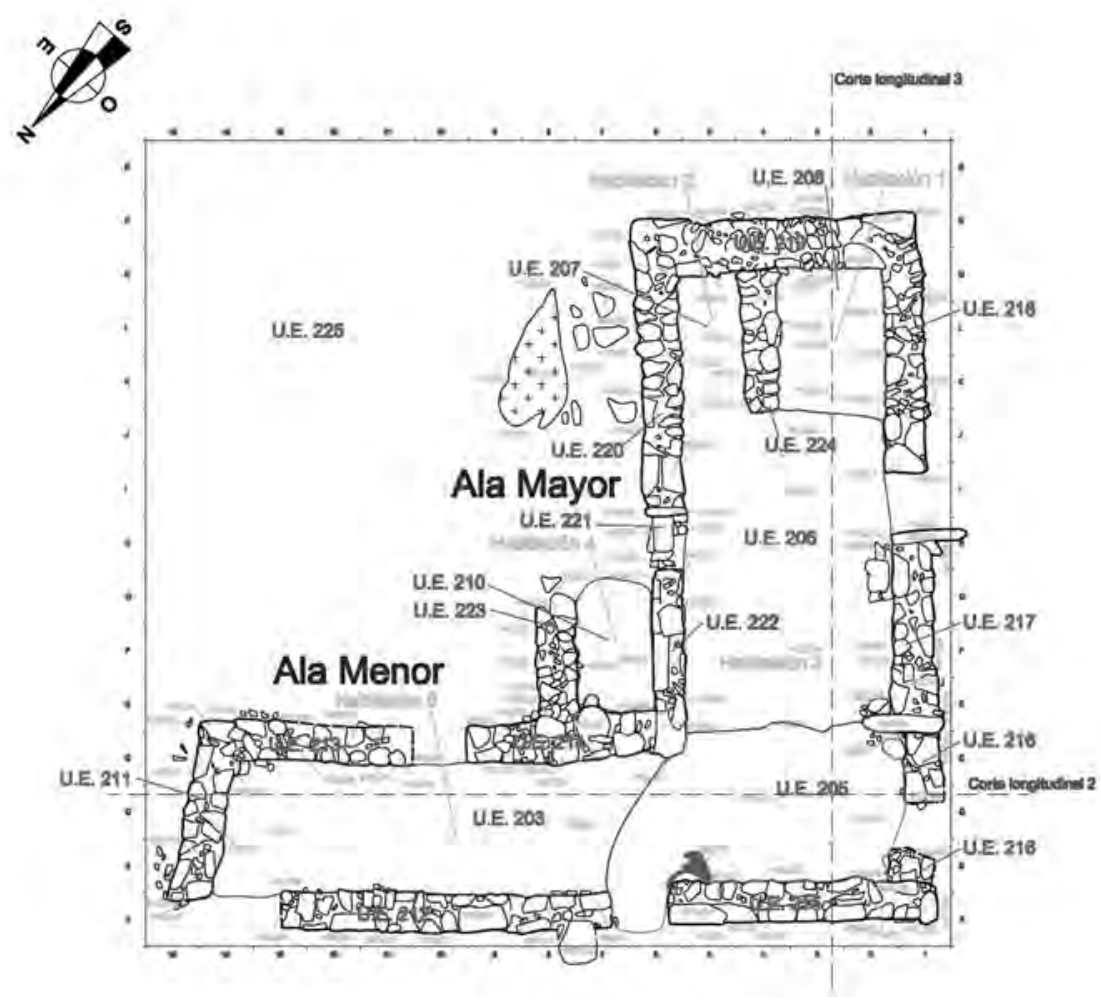

Figura 2 - Estructura 4 de Los Cepones (Strato 2002)

\subsection{Las ocupaciones en altura}

Un fenómeno ampliamente constatado en toda Europa Occidental a partir de la cuarta centuria es la ocupación o reocupación de espacios en altura relativa (Quirós Castillo e Tejado Sebastián 2012) cuya interpretación ha sido muy diversa. En la cuenca del Duero se han localizado un número muy significativo de estos contextos que han sido vinculados a espacios de élites políticas relacionadas con la articulación del territorio a partir de la desestructuración de las antiguas civitates imperiales (Castellanos e Martín Viso 2005).

En nuestra zona de estudio encontramos, sin embargo, únicamente dos casos conocidos arqueológicamente. Sobre el sitio del Cerro de la Virgen del Tormejón (Armuña, Segovia) contamos con algunas informaciones aisladas que parecen señalar su ocupación en época altomedieval. Se trata de un asentamiento en altura con ocupación en la Prehistoria Reciente pero que debió ser abandonado 
durante la época imperial. Ya en 1971 Antonio Molinero recogió algunos materiales altomedievales de la zona de la Armuña, posiblemente de este cerro, que fueron luego republicados y ampliados por Juan Tovar y Blanco García (Juan Tovar e Blanco García 1997: 174; 212ss; Molinero Pérez 1971). Las prospecciones y análisis llevados a cabo por Gozalo Viejo a finales de los 70 parecen confirmar esta ocupación altomedieval (Gozalo Viejo 1980). Ocupación que, sin embargo, sólo se conoce, a falta de más información, por la presencia de las cerámicas estampilladas.

Algo más de información se tiene del cerro de Bernardos, en la localidad del mismo nombre. Se trata de una superficie amesetada en altura en el valle del río Eresma que fue objeto de excavaciones a finales de los años $80 \mathrm{y}$, posteriormente, entre los años 1996-2000 (Fuentes Domínguez et alii 2008; Gonzalo González 2007). El aspecto más destacado a nivel estructural de Bernardos es el doble recinto de muralla que rodea el asentamiento. $\mathrm{El}$ más interno es un lienzo con varios tramos diferenciados; del más monumental se conservan hasta dos metros de altura y 3,5 m de espesor. Cuenta con bastiones semicirculares situados a lo largo de la línea de muralla. Está construida fundamentalmente a base de pizarra y sillares de material calizo posiblemente reutilizados. Se han constatado posibles reparaciones en algunos tramos, incluida la construcción de lo que se ha identificado como un "paso de ronda", lo que parece indicar una ocupación dilatada de este espacio y un gasto significativo para el mantenimiento de esta muralla.

Las excavaciones se llevaron a cabo principalmente en la cara interna de la muralla, documentándose una serie de muros apoyados contra ella, construidos en lajas de pizarra y muros de mampostería, que han sido relacionados con espacios de habitación. Uno de los espacios contaba con dos habitaciones y dos vanos de acceso, uno de ellos con acceso desde el paso de ronda. Este espacio se ha datado en las primeras fases del yacimiento, a mediados del siglo $\mathrm{v}$, aunque una de las habitaciones podría ser posterior.

Un aspecto muy destacado del contexto de Bernardos es el conjunto cerámico recuperado. Este conjunto mostraría, según Gonzalo González, la evolución cerámica entre los siglos $\mathrm{v}$ hasta mediados del IX sin interrupciones significativas (2007: 37ss), lo que nos ofrecería un contexto de ocupación que sobrepasaría el fatal "siglo viri", así como una información muy interesante sobre los patrones de ocupación de los primeros momentos de implantación del Estado islámico.

\section{INTERPRETACIÓN: HIPÓTESIS SOBRE EL PROCESO HISTÓRICO}

Los contextos presentados y la propuesta de delimitación cronológica (figura 3) nos permiten hacer una serie de valoraciones e hipótesis sobre los procesos históricos ocurridos en el centro peninsular entre los siglos IV y IX.

Como se ha afirmado en otras publicaciones (Quirós Castillo e Vigil-Escalera 2006; Tejerizo García 2011), se observa arqueológicamente un profundo cambio 
en la segunda mitad de la quinta centuria cuyos indicadores principales son tres: el final de las villas latifundistas, la (re)ocupación de los espacios en altura y el surgimiento de un nuevo tipo de poblamiento en la forma, principalmente, de aldeas y granjas.

Almenara de Adaja
Los Casares
Soto de Tovilla
Carratejera
Roda de Eresma
Coca
Las Pizarras
5.juan de los Caballeros
Segovia
El Cantosal
Madrona
Espirdo-Veladiez
Lenovilla
Ladera de los Prados
Carcava de la Peladera

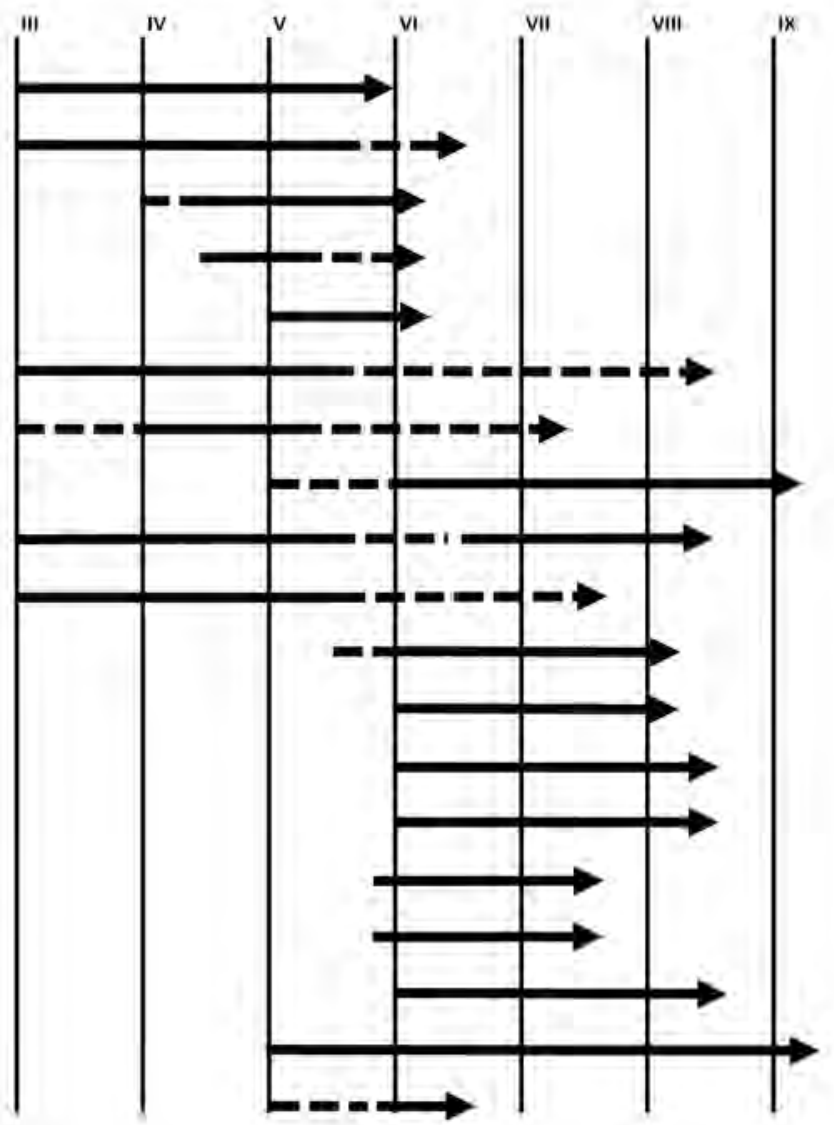

Figura 3 - Propuesta cronológica de los yacimientos analizados.

El concepto "final" de las villas latifundistas se refiere al fin de un tipo determinado de poblamiento relacionado con la forma de explotación hegemónica en época tardoimperial, no al final de la ocupación de un mismo espacio geográfico. En efecto, en muchas de estas villas tardoimperiales del centro peninsular se constata una continuidad en la ocupación de los espacios, ya sea a través de la reutilización o reocupación de espacios con fines domésticos, la presencia de necrópolis amortizando las estructuras o, más efímeramente, a través de la presencia de producciones cerámicas dentro de los ciclos tecnológicos medievales 
(Chavarría Arnau 2007; 2008). Sin embargo, este tipo de ocupaciones no responden ya a un poblamiento dedicado a la centralización y comercialización de excedentes, sino a una nueva forma de ocupación del territorio. Se trataría de comunidades que aprovechan los antiguos espacios vilicarios en función de las necesidades de sus estructuras económicas y sociales, radicalmente distintas a las necesidades estructurales de una economía imperial como la romana. Estas reocupaciones podían servir a las nuevas comunidades tanto a nivel funcional, reutilizando materiales (teja y ladrillo) y espacios (estructuras murarías y habitaciones), como a nivel simbólico, con la ocupación de antiguos espacios de prestigio que legitimaran el nuevo tipo de poblamiento. En cualquier caso, lo importante es constatar el radical cambio que se produce en el tipo de poblamiento, y que se relaciona con la desestructuración del entramado económico imperial, el cambio en las formas de propiedad de los espacios y la reestructuración social de las comunidades que ocuparon estos espacios.

Quedaría aún por determinar el carácter de los asentamientos del tipo de Soto de Tovilla o Carratejera. ¿Forman parte del entramado de la economía imperial en la forma de pequeños asentamientos rurales dependientes (o independientes) de la centralización latifundista? ¿ $\mathrm{O}$ son más bien un reflejo de este proceso de desestructuración sistémica? Por el momento, no se puede más que apuntar la posibilidad de que puedan formar parte de este proceso de transición entre un sistema de poblamiento y otro aunque en mi opinión, y en función de los datos conocidos, ya no formarían parte del mundo imperial.

El fenómeno de las necrópolis postimperiales pueden ser analizadas desde este punto de vista de desestructuración de la economía y la sociedad tardoimperial (Tejerizo García 2011; Vigil-Escalera 2010). Los importantes cambios en los sistemas de propiedad y en la estructuración social llevarían a las comunidades rurales y a sus élites a situaciones de tensión político-social (Halsall 2011) en los que se haría necesaria la justificación y legitimación de la posición social de algunos personajes dentro de las comunidades y de la dependencia del resto mediante la amortización simbólica de elementos "prestigiosos". El uso del vidrio en Roda de Eresma es particularmente interesante en este sentido ya que mostraría la amortización de un elemento de difícil acceso y cada vez menos frecuente, al menos, en el mundo rural ${ }^{12}$.

En torno a este "mediados de la quinta centuria" se constatan igualmente las conocidas ocupaciones de espacios en altura (caso de Bernardos y el Cerro de la Virgen, pero también de prácticamente todos los ejemplos en la Cuenca del

\footnotetext{
${ }^{12}$ No ocurriendo lo mismo en ciudades como Recópolis o Toledo (Castro e Gómez 2008). Al contrario de lo que opina Fuentes Domínguez pienso que el vidrio no era un material "económicamente asequible a la población" (1989: 229) y que en este tipo de contextos se rarificarían de forma sustancial a partir de la quinta centuria, sobre todo por la significativa escasez, que no ausencia, de este tipo de material en los contextos de los siglos VI-VIII.
} 
Duero) que se han relacionado con un clima de inestabilidad política y militar, que llevó a las élites tardoimperiales a buscar refugio en espacios fortificados. La contemporaneidad de este proceso con la evidente desestructuración de los centros urbanos, de los que Segovia y Coca serían ejemplos paradigmáticos, no hace sino corroborar aparentemente esta interpretación. Sin embargo, las excavaciones (todavía escasas) en algunos de estos entornos (Quirós Castillo e Tejado Sebastián 2012) muestran un tipo de poblamiento muy estable en el espacio y en el tiempo que aunque tuviera un inicio relacionado con actividades militares (cuestión, por otro lado, muy difícil de demostrar arqueológicamente), pronto adquiriría otras funcionalidades. El tipo de materialidad y los ciclos tecnológicos reflejados en estas ocupaciones muestran una fuerte capacidad para acaparar capital social y económico (las murallas de Bernardos podrían ser un ejemplo) muy diferentes a los atestiguados en los asentamientos rurales que deben ponerse en relación con diferencias en cuanto al estatus y funcionalidad de estos centros con respecto a los asentamientos rurales. Es indudable que la falta de excavaciones limita mucho la capacidad de análisis (¿dónde se enterraban estas comunidades? ¿qué tipo de economía y estructura social permitía su producción y reproducción?), pero los datos arqueológicos parecen mostrar algún tipo de centralidad de estos espacios en la articulación política y económica de los territorios. Centros que, de tener esta funcionalidad político-administrativa (una especie de sustitutos contextuales de las antiguas civitates romana, aunque de carácter radicalmente distinto) tendrían que ser numerosos en el espacio entre el Adaja y el Eresma, si se atiende a la escasa distancia que media entre Bernardos y el Cerro de la Virgen (escasos $5 \mathrm{~km}$ ). Otra posibilidad es que la variabilidad de estos centros sea mayor de lo que se cree y que mientras que algunos $(¿ \dot{i B r n a r}-$ dos?) pudieran ejercer este papel articulador, otros podrían ser ocupaciones por parte del mismo tipo de comunidades que ocupan los asentamientos rurales, sin funcionalidad articuladora, aunque de momento no tenemos datos para confirmar o refutar esta hipótesis.

Uno de los elementos más significativos de este período es la emergencia de un tipo de poblamiento basado en las relaciones sociales de tipo comunitario y de pequeña escala cuyo inicio, al menos en el área de estudio (y que podríamos extender a gran parte de la cuenca del Duero), se puede datar a partir de mediados de la quinta centuria. A partir del siglo vi parece consolidarse este tipo de poblamiento cuya base social e identitaria se encuentra en la unidad doméstica, centro de las relaciones sociales de producción y de la gestión de una propiedad privada junto con otra pública. Un tipo de poblamiento que sería reflejo, al menos en sus primeras etapas, de ese incremento de la capacidad de gestión de los procesos productivos por parte del campesinado propuesta por C. Wickham (2005) y que se desarrollaría de forma distinta según el contexto socioeconómico concreto. En nuestro caso de estudio la presencia de asentamientos de cierta “especialización” económica, como La Mata del Palomar o Los Cepones, junto 
con otros más pequeños, como Cárcava de la Peladera, podría indicar una cierta inserción de esta área en escalas de poder extralocales (de nuevo, ¿Bernardos?) que gestionarían y dirigirían la actividad de algunos de estos asentamientos.

Esta presencia de varias escalas de producción y reproducción social dentro de los mismos contextos podría ser una vía explicativa para las necrópolis altomedievales hasta la octava centuria (Tejerizo García 2011). La presencia de elementos de ajuar de tipo personal que hacen referencia explícita al centro de poder toledano funcionarían como elementos de prestigio, en la forma de "dones y contradones", que reforzarían estos vínculos clientelares con ciertas unidades domésticas de las comunidades rurales. De esta manera se explicarían las diferencias internas a la hora de acceder a esta materialidad al mismo tiempo que explicaría por qué existen necrópolis con escasos elementos de ajuar (como ocurre, por ejemplo, en necrópolis como El Cantosal). La consolidación de la estructuración social y las escalas de poder a partir de la séptima centuria, momento coincidente con la consolidación de la "red aldeana" (Quirós Castillo e Vigil-Escalera 2006), modificaría sustancialmente el lenguaje simbólico en estas necrópolis hacia una aparente "igualdad" en la ritualidad aunque igualmente reflejo de una compleja estratificación social (Tejerizo García 2011).

Si bien el inicio de todo este proceso es más o menos claro, su final es más complicado de detectar y de explicar. La enorme dificultad para la datación y secuenciación de los asentamientos rurales, debido a la falta de herramientas más precisas, es especialmente influyente a la hora de definir los procesos finales de este tipo de poblamiento. Todo parece apuntar a una desestructuración de este sistema en la octava centuria, pero no es más que una vaguedad determinada por tradiciones historiográficas como el de las invasiones musulmanas y la "despoblación del Duero", superadas en la teoría pero muy influyentes en la praxis arqueológica. La presencia islámica únicamente se ha podido documentar en Bernardos, y por lo que se puede observar en otras zonas de la cuenca del Duero, parece que este tipo de centros articuladores fueron el objetivo principal del estado islámico al norte del Sistema Central. Desechando las tesis de cualquier tipo de despoblación total de la zona del Duero, se plantearía la hipótesis de una posible continuidad de algunos de los asentamientos rurales altomedievales a lo largo de la octava centuria, pero con un carácter distinto quizá asociado a una restricción de las escalas de acción social y política. Esto encajaría, por otra parte, con el sistema de poblamiento contemporáneo a los procesos de construcción de las primeras estructuras políticas altomedievales.

\section{Conclusiones}

El desarrollo de la Arqueología Comercial entre mediados de los 90 y los primeros años de la nueva centuria ha proporcionado una ingente cantidad de información arqueológica. En el caso de la Alta Edad Media este fenómeno ha 
sido, paradójicamente, un punto y aparte en la posibilidad de formular hipótesis sobre los procesos históricos de este período. Hipótesis que anteriormente habían tenido que restringirse a los datos provenientes, fundamentalmente, de las prospecciones arqueológicas.

El territorio entre los ríos Eresma y el Adaja, en la zona central de la cuenca del Duero, es un área especialmente densa en yacimientos arqueológicos excavados desde el que se ha podido hacer una aproximación a este proceso histórico de transición entre la economía tardoimperial romana y los primeros momentos de la Alta Edad Media. Esta hipótesis tiene como eje fundamental la desestructuración del entramado económico imperial a lo largo de la quinta centuria que produjo un fuerte cambio de escala (sensu Escalona Monge 2011) cuya consecuencia fue un cambio en el sistema de poblamiento en el que los asentamientos rurales, las granjas y aldeas, formaron el núcleo de articulación básico del territorio estudiado y de gran parte de la Península Ibérica.

Es indudable la enorme cantidad de problemas sin resolver y que requieren, no tanto de más datos, sino de una crítica sobre los mismos bajo nuevos paradigmas teóricos; pero es igualmente indudable que estamos en disposición en la actualidad de los datos suficientes como para ofrecer narrativas históricas coherentes sobre este proceso de transición histórica. 


\section{BibLiografía}

ALONSO ÁVILA, Á. (1984-1985) Aproximación a la época visigoda en el territorio de la actual provincia de Segovia. Studia Histórica: Historia Antigua 2-3, p. 271-290.

BLANCO GARCÍA, J. F. (1997) Aproximación a la Cauca del bajo Imperio. Congreso Internacional La Hispania de Teodosio (vol. 2). Segovia, p. 377-393.

BLANCO GARCÍA, J. F. (2010) La ciudad de Cauca y su territorio. In: Martínez Caballero; Caballero; Santiago Pardo; Zamora Canellada (eds) Segovia Romana II. Gentes y territorios. Segovia, p. 221-249

CASTELLANOS, S.; MARTÍN VISO, I. (2005) The local articulation of central power in the north of the iberian Peninsula (500-1000). Early Medieval Europe, 13 (1), p. 1-42.

CASTRO, M., e GÓMEZ, A. (2008) La actividad artesanal en Recópolis: la producción de vidrio. In: Olmo (ed.) Recópolis y la ciudad en la época visigoda. Alcalá de Henares, p. 117-128.

CHAVARRÍA ARNAU, A. (2007) El final de las villae en Hispania (siglos IV-VII d.C). Turnhout.

CHAVARRÍA ARNAU, A. (2008) Villae tardoantiguas en el valle del Duero. In: Castellanos; Martín Viso (eds.) De Roma a los Bárbaros. Poder centraly borizontes locales en la Cuenca del Duero. León, p. 93-122

ESCALONA MONGE, J. (2011) The Early Middle Ages: a scale-based approach. In: Escalona Monge; Reynolds (eds.) Scale and scale change in the Early Middle Ages. Exploring landscape, local society, and the world beyond. Turnhout, p. 9-30.

FUENTES DOMÍNGUEZ,Á. (1989) La necrópolis tardorromana de Albalate de las Nogueras (Cuenca). Cuenca.

FUENTES DOMÍNGUEZ,Á.; BARRIO MARTÍN,J.; GONZALO GONZÁLEZ, J. M. (2008) Memoria de investigación de los trabajos en el yacimiento arqueológico del Cerro del Castillo (Bernardos, Segovia). Campañas de 1996, 1997, 1998, 1999, 2000. Informe depositado en el Servicio Territorial de Cultura de Segovia.

GARCÍA MERINO, C., e SÁNCHEZ SIMÓN, M. (2004) De nuevo acerca de la villa romana de Almenara de Adaja (Valladolid): excavaciones de 1998 a 2002. Archivo Español de Arqueología 77, p. 177-195.

GARCÍA MERINO, C.; SÁNCHEZ SIMÓN, M. (2011) Una tumba femenina con ajuar de la villa romana de Almenara de Adaja (Valladolid). Zephyrus LXVIII, p. 239-255. 
GONZALO GONZÁLEZ, J. M. (2007) El Cerro del Castillo, Bernardos (Segovia). Un yacimiento arqueológico singular en la provincia de Segovia durante la Antigüedad Tardía. Segovia.

GOZALO VIEJO, F. (1980) El yacimiento del Cerro Tormejón. Armuña, Segovia. Memoria de Licenciatura inédita, Departamento de Prehistoria y Arqueología, Universidad Autónoma de Madrid.

HALSALL, G. (2011) Ethnicity and early medieval cemeteries. Arqueología y Territorio Medieval 18, p. 15-28.

ISLA FREZ, A. (2000-2001) Desde el reino visigodo y la ortodoxia toledana: la correspondencia de Montano. Studia Histórica: Historia Medieval 18-19, p. 41-52.

JEPURE, A. (2004) La necrópolis de época visigoda de Espirdo-Veladiez: Junta de Castilla y León.

JEPURE, A. (2012) Das westgotenzeitliche Gräberfeld von Madrona (Segovia, Spanien). Würzburg.

JUAN TOVAR, L. C.; BLANCO GARCÍA, J. F. (1997) Cerámica común tardorromana, imitación de sigillata, en la provincia de Segovia. Archivo Español de Arqueología 70, p. 171-219.

LUCAS DE VIÑAS, M. d. R. (1971) La necrópolis de "El Cantosal", Coca (Segovia). Noticiario Arqueológico Hispánico XVI, p. 383-396.

MAÑANES PÉREZ, T. (1992) La villa romana de Almenara-Puras (Valladolid). Valladolid.

MARCOS CONTRERAS, G. J.; SANZ GARCÍA, F. J.; MISIEGO TEJEDA, J. C.; MARTÍN CARBAJO, M. Á.; DEL CAÑO GARCÍA, L. Á. (2010) La ocupación tardorromana en el yacimiento de Carratejera, en Navalmanzano (Segovia). In: Martínez Caballero; Santiago Pardo; Zamora Canellada (eds) Segovia Romana II. Gentes y territorios. Segovia, p. 379-392.

MARTÍN RODRÍGUEZ, E. M.; SAN GREGORIO HERNÁNDEZ, D. (2008) La necrópolis tardorromana del Soto de Tovilla (Tudela de Duero, Valladolid). Estudios del Patrimonio Cultural 1, p. 19-32.

MARTÍNEZ CABALLERO, S.; SANTIAGO PARDO, J. (2010) La ocupación del territorio segoviano en época imperial romana (ss. I-V d.C). In: Martínez Caballero; Santiago Pardo; Zamora Canellada (eds.) Segovia Romana II. Gentes y territorios. Segovia, p. 75-118.

MOLINERO PÉREZ, A. (1950) Diez años de arqueología segoviana. Estudios Segovianos II-III, p. 639-652. 
MOLINERO PÉREZ, A. (1971) Aportaciones de las excavaciones y hallazgos casuales (1941-1959) al Museo Arqueológico de Segovia. Excavaciones Arqueológicas en España 72.

QUIRÓS CASTILLO, J. A. (Ed.) (2013) El poblamiento rural de época visigoda en Hispania. Arqueología del campesinado en el interior peninsular. Bilbao.

QUIRÓS CASTILLO, J. A.; TEJADO SEBASTIÁN, J. M. (2012) Los castillos altomedievales en el noroeste de la Peninsula Ibérica. Bilbao.

QUIRÓS CASTILLO, J. A.; VIGIL-ESCALERA, A. (2006) Networks of peasant villages between Toledo and Velegia Alabense, Northwestern Spain (V-Xth centuries). Archeologia Medievale XXXIII, p. 79-128.

REGUERAS GRANDE, F.; DEL OLMO, J. (1997) La villa de los Casares (Armuña, Segovia): Propuestas de lectura. In: Teja; Pérez (eds.) Congreso Internacional La Hispania de Teodosio. Segovia, p. 675-686.

RODRÍGUEZ LÓPEZ, M. I. (2010) Materiales arqueológicos de la villa romana de los Casares en Armuña, Segovia (2005-2007). Bollettino di Archeologia I, p. 126-134.

SANTIAGO PARDO,J.; MARTÍNEZ CABALLERO, S. (2010) La ciudad de Segovia y su territorio. In: Martínez Caballero; Santiago Pardo; Zamora Canellada (eds.) Segovia Romana II. Gentes yterritorios. Segovia, p. 143-180.

STORCH DE GRACIA, J. J. (2010) La villa imperial de Los Casares en Armuña (Segovia). In: Martínez Caballero; Santiago Pardo; Zamora Canellada (eds.) Segovia Romana II. Gentes y territorios. Segovia, p. 363-377.

STRATO (2002) Excavación arqueológica en el yacimiento de Los Cepones (T.M. La Losa, Segovia) afectado por el trazado de la autopista de peaje conexión A-6 (San Rafael) a Segovia. Informe depositado en el Servicio Territorial de Cultura de Segovia.

(2003) Excavación arqueológica en el yacimiento de Carratejera, afectado por la construcción de la variante de Navalmanzano, CL-601 (Segovia). Informe depositado en el Servicio Territorial de Cultura de Segovia.

(2007) Excavación en área en el yacimiento de "Senovilla" (T.M. Olmedo, Valladolid). Informe inédito depositado en el Servicio Territorial de Cultura de Valladolid.

TEJERIZO GARCÍA, C. (2011) Ethnicity in early middle age cemeteries. The case of the "visigothic" burials. Arqueologia y Territorio Medieval 18, p. 29-43.

VIGIL-ESCALERA, A. (2007) Granjas y aldeas altomedievales al norte de Toledo (450-800 d.C). Archivo Español de Arqueología 80, p. 239-284. 
(2009) Apuntes sobre la geneología política de aldeas y granjas altomedievales. In: Martín Viso (Ed.) $\dot{\zeta}$ Tiempos oscuros? Territorios y sociedad en el centro de la Peninsula Ibérica (siglos VII-X). Madrid, p. 31-44

(2010) El yacimiento arqueológico de Cabriana. La Necrópolis Postimperial. Estudios mirandeses: anuario de la Fundación Cultura, p. 179-194.

VIGIL-ESCALERA, A. (2011) El pequeño mundo en ruinas de la Arqueología contractual española. Revista Arkeogazte 1, p. 17-20.

WICKHAM, C. (2005) Framing the Early Middle Ages. Oxford. 